\title{
Indigenous Knowledge Perspective on Holistic Education and Sustainable Development
}

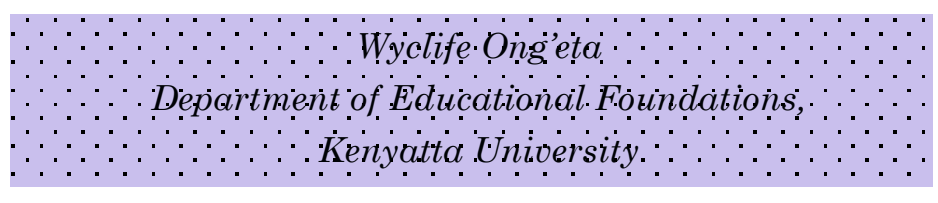

\section{Abstract}

The potential for education to engender development and therefore to provide individuals and communities with opportunities to lift themselves out of poverty is, correctly, stressed throughout contemporary development literature (Subtle, 2009). In confronting the many challenges in the planet, humankind sees in education an indispensable asset in its attempt to achieve ideals of peace, freedom and social justice. In Kenya, Ochieng (2012) contends that citizens are highly educated yet the education is academic only given that socially we are probably the world's most ignorant group. Ours is an extremely bad education system as innovation systems do not effectively serve critical national needs. This paper points out that the only way we can fix challenges hindering sustainable development of Kenya is by adapting our colonial 
education system to enable the young citizenry find identity, meaning, and purpose in life through connections to the community, to the natural world, and to spiritual values. This paper will explore indigenous education systems to interrogate how communities have generally relied on their vast indigenous knowledge and technology to interact with the environment as well as stable coexistence with their immediate environment thus maintaining ecological equilibrium with quality life. Furthermore, the paper will give suggestions that will help educators, policymakers and educational stakeholders to advocate for a holistic system of education that will accelerate Kenya's sustainable development and achievement of Vision 2030.

\section{Introduction}

In confronting the many challenges that the future holds in store, humankind sees in education an indispensable asset in its attempt to attain the ideals of peace, freedom and social justice (UNESCO, 1993). Furthermore, UNESCO notes that education is the principal means available to foster a deeper and more harmonious form of human development and thereby to reduce poverty, 
exclusion, ignorance, oppression and war as well as espousing sustainable development initiatives. However, in many societies, Ochieng (2012) posits that members are highly educated yet our education is academic only given that socially, morally and spiritually we are probably the world's most ignorant group. The same view is expounded by Mosha (2000) that most world leaders are "well educated" but justice and peace continue to escape us and billions of people are not anywhere close to a life fully alive, fully human.

Most of the elites running the government and education sector as Nyambura (2008) noted were schooled in colonial schools and thus find it difficult to break away from the past. She further observes that the syllabus continues to glorify the virtues of "modernity" which is seen as westernisation at the expense of the traditional lore. Scholars like Crawford and Rossiter (1993) argue that over-emphasis on employment-oriented competencies may eclipse the attention that should be given to aspects of education concerned with personal development in the rich sense of the concept including physical, personal, social, spiritual and moral development. Crawford and Rossiter (1993) posit that school curricula, no 
matter how successful they may be in achieving new target levels of equity, retention and measurable employment-related competencies, will remain flawed if they fail to give a prominent place to studies concerned with human meaning and values.

According to Skattom (2009) western worldview and languages have long dominated educational systems in Africa and other developing countries, and the enormous gap this creates between school and home is one of the reasons for the drop-outs, repeating and poor school results even for those who come through the system, which undermine the important financial resources actually allotted to the education sector both by the countries themselves and international donors. It is a sad fact that illiteracy still prevails in these parts of the world. And as we know, illiteracy constitutes a main barrier to development in important sectors like health, the working world, economic life and not least democracy.

Most contemporary discussions on
indigenous knowledge rest in the shadow of
Western globalization ideas about structural
adjustment, etc and congruently it is projected as a


stagnant, limited, and inoperative paradigm which pushes some to conclude that any serious discussion about the indigenous transmission of values and its accumulated knowledge in Africa is a waste of time. However, via an African centered synthesis one can begin to appreciate the particulars of indigenous ways of knowing and their epistemologies (Zulu, 2006).

It is my contention that the education system we inherited from the colonial government be blended with salient indigenous knowledge that connect the mind, soul and the body as well interconnecting the community to the natural world and to spiritual values to address the hiatus discussed above. Perhaps, as GoK (2007) observes, "people can draw wisdom from the long established indigenous beliefs and traditions that with different contexts and structures, have formed the basis for a life in harmony with nature." Indeed it should be noted that indigenous knowledge produces a whole person as well as espousing peaceful coexistence, an ingredient of sustainable development of all inhabitants living in the planet.

Through sustainable development, UNDSD (2005-2014) contends that we could meet the needs 
of the present without compromising the ability of future generations to meet their own needs. It will contribute to enabling citizenry to face the challenges of the present and future and leaders to make relevant decisions for a viable world. These actors will have acquired various skills (critical and creative thinking, communication, conflict management and problem solving strategies, project assessment) to take an active part in and contribute to the life of society; be respectful of the Earth and life in all its diversity and be committed to promoting democracy in a society without exclusion and where peace prevails.

UNESCO (2007) notes that the transition towards a more sustainable future begins with each and every person making informed choices for a better understanding of how our present production and consumption patterns impact the planet's natural resources. It also implies the ability and capacity of different peoples around the world (and future generations) to meet their needs.

Holistic education is the true means through which sustainable development can be achieved. It enables people to develop the knowledge, values and skills to participate in decisions about the way 
we do things, individually and collectively, locally and globally, that will improve the quality of life now without damaging the planet of the future (UNDSD, 2005-2014). This kind of education as Mosha (2000) observes, advances the human innermost spiritual dimension and its off springs: intuition, inspiration, the inner voice, and the ever present human search for the transcendent meaning of life and the world. As Susan (2012) asserted:

Applying holistic thinking to all humankind's activities is a complex task. Yet, the failure to do so has created serious ecological imbalances and environmental degradation. Ultimately, environmentally destructive behavior is the result of a failure to recognize that human beings are an inseparable part of Nature and that we cannot damage it without severely damaging ourselves. People can draw wisdom from the longestablished indigenous beliefs and traditions that, within different contexts and structures, have formed the basis for a life in harmony with nature. The "holistic vision" inherent in all of them and the importance given to being in constant communion with nature is perhaps one of their key lessons.

It is important to mention that indigenous knowledge is a means to sustainability due to its 
interconnectedness with various facets of life as well as local patterns resources use. As Ashok (2011) contends a civilized body has so many things to be learnt from indigenous knowledge system of a nature-bound community, especially at this high time when this planet has severely suffered from so many problems like pollution, global warming, loss of biodiversity, war and economic crises, increasing economic diversity and subsequent fuel and food crises and at the end, use of genetically modified food, bio-piracy, etc.

\section{Indigenous Knowledge in Sustainable Development}

Indigenous knowledge as Mapara (2009) observes is a body of knowledge, or bodies of knowledge of the indigenous people of particular geographical areas that they have survived on for a very long time. According to Asma (2012): "The long -standing traditions and practices of certain regional or local communities, constitutes a cumulative body of knowledge, wisdom, moral values, know-how, practices, and representations maintained and developed by peoples with 
extended histories of interaction with the natural environment." In light of the definitions above of indigenous knowledge, one can arrive at the following facets of Indigenous Knowledge Systems that appear to be more or less explicit to indigenous knowledge:

- Utilitarian in nature;

- Culture and context-specific;

- Tacit and practical knowledge;

- Transmitted orally from one generation to another;

- Formative and develops the whole person;

- Dynamic, adaptive, resilient and time-tested;

- Holistic - it cannot be compartmentalized and cannot be separated from the people who hold it as well as rooted in the spiritual health, culture and language of the people.

This kind of knowledge as UNESCO (2010) pointed out has been the basis for agriculture, food preparation, health care, education, conservation and a wide range of other activities that sustain societies in many parts of the world. It espoused the ideals of peace, freedom and social justice as 
well as enabled the youngsters have identity, meaning and purpose in life through connections to the community, natural world and the spiritual world. It is worth mentioning that integrating indigenous knowledge in our education system will go a long way in nurturing and moulding an all round citizenry and the ideals of peace, sustenance, innovativeness and social justice that are salient for sustainable development. These skills, knowledge and attitudes, for instance as Ocholla (2010) notes when shared, adapted and refined, sustain communities and bring sustainable development in areas such as:

- Healing (e.g. alternative/traditional/herbal medicine; physical and mental fitness - the Maasai's treatment of foot-and-mouth disease; the Fulani's treatment of cattle ticks with Euphorbia plants)

- Nutrition (e.g. vegetarian cuisine; the Hoodia stem/cactus used by San people to stave off hunger and control thirst on hunting trips)

- Wealth, income and business (e.g. intellectual property, tourism, the informal sector or small, medium and micro-enterprises) 
- Education (e.g. customs, traditions, culture, language)

- Entertainment (e.g. traditional music and dance)

- Politics (conflict resolution through an indaba, baraza, imbizo, kgotla, etc.)

- Architecture and design (some wonderful African architecture exists in Egypt and South Africa; clothes/attire), and countless more.

Reagan (2005), discussing traditional African educational thought and practice observed that it is characterised not only by its concern with the whole person but also by its interweaving of social, economic, political, and educational threads together into a common tapestry. Morally as scholars like Bogonko (1992) aptly put it, "the child was governed by clearly spelt out groups of avoidances, prohibitions and permissions, or simply a strict code of morality, on which individual and ethnic group welfare depended. These rules and actions were aimed at predetermining conduct and carried with them a spirit of discipline and moral sustainability." 
Writing about traditional systems of education in Africa, Sifuna (2006) observed that indigenous education was guided by the principle of "learning by doing". Children received functional learning which largely prepared them to live and work on the land as well as in specialised occupations. For instance, through apprenticeships and participation in the world of work, children developed physical endurance skills, a sense of observation and good memory as well as reliance. In his outstanding study of indigenous knowledge systems in Zimbabwe, Mapara (2009) began by noting that indigenous people developed traditional ways of weather forecasting that helped them to plan their activities for at least two to three days in advance. This knowledge was very useful especially in summer and immediately after harvesting when crops like finger millet would be in need of thrashing and winnowing in an effort to have sustainable food reserves to combat hunger.

Indigenous ways of knowing as Mapara (2009) observes have also brought forth useful knowledge on medicine and health. In fact, their resilience in this area led to the recognition that traditional healers or alternative medical practitioners got to date. For instance, among the 
Shona of Zimbabwe, when one was suffering from malaria, plants like chiparurangoma (borreria dibrachiata) were used for treatment. It was administered orally and one was usually healed of the ailment within twenty-four hours. Mapara further notes that the Shona used the shrub called muvengahonye (canthium huillense) to treat and heal wounds that had become septic on both human beings and livestock. Other plants like chikohwa/ gavakava (aloe) were and continue to be used to heal people who are suffering from stomach ailments. The same plant was, and in some places continues to be used as preventive medicine for new castle disease in chickens.

Taboos promoted preservation as Cheserek (2005) posits of environment. For instance some birds were not killed and certain plants were not used for firewood. The Marakwet prohibited the cutting of live trees and preferred dead wood, except in circumstances such as when mending a bee-hive or cattle trough. Most indigenous trees were also considered sacred and were used to perform rituals. This practice ensured trees grew to maturity hence, the preservation of water catchments. The community also encouraged the planting of indigenous trees around rivers and 
streams to reduce direct interference from human activity and that of livestock and wild animals. Although this may have increased evapotranspiration, these trees ensured that water courses were not eroded during heavy rainfall.

Cheserek (2005) further notes that Marakwet purified dirty water using local shrubs/ herbs such as 'chepluswo' (maerua edulis). Interestingly this technique worked and immediately the water became pure. Women also inserted burnt ash into water pots to settle any dirt and make the water sweet. Occasionally, the water storage pots were cleaned and put outside to dry facing upside down. In addition, Emeagwali (2003) contends that at the level of economic sustainability, self-reliance, and cost effectiveness, indigenous knowledge continues to prove its viability and strength. Blending indigenous and modern technologies enhances the ecological sustainability of the results as IFAD (2003) pointed out leading to production increase, better quality products and new products.

According to Sifuna (2006) indigenous knowledge also inculcated a very religious attitude to life. Religion, which was mainly concerned with 
morality, gave support to the laws and customs of the community and its accepted rules of conduct. This includes courtesy, generosity and honest. Individuals had to learn when to use or avoid the ancestral spirit and other mysterious powers for the sake of their sustainable livelihood as well as social cohesion. As UNESCO (2010) observes, social cohesion has been the key to survival for many indigenous cultures. Food gathering and hunting depend on mutual support and co-operation and disharmony within a part of the group is dangerous to the whole. In many cultures men and women have developed complementary, if not equal, roles; political decisions are arrived at by consensus in many cultures, and other social arrangements that benefit the entire community have often been incorporated into indigenous cultural traditions.

For indigenous people, the land was the source of life - a gift from the creator that nourishes, supports and teaches. Although indigenous peoples vary widely in their customs, culture, and impact on the land, all consider the Earth like a parent and revere it accordingly. 'Mother Earth' is the centre of the universe, the core of their culture, the origin of their identity as a people. She connects them with their past, present, 
and future (as the legacy they hold in trust for their children and grandchildren). In this way, indigenousness carries with it a sense of belonging to a place. At the heart of this deep bond is a perception, awareness, that all of life - mountains, rivers, skies, animals, plants, insects, rocks, people - are inseparably interconnected. Material and spiritual worlds are woven together in one complex web, all living things imbued with a sacred meaning (UNESCO, 2010). It is worth to mention that the interconnectedness existed between indigenous people and nature, indigenous people and spirituality was the key to sustainable livelihood and harmonious coexistence; it was and it is the engine to sustainable development of any country in the planet.

\section{Indigenous Means of Transmitting Knowledge}

According to Mapara (2009) the other means Africans used to teach their youngsters included among others proverbs, riddles, folktales, songs, legends and myths. Proverbs can be defined as summary statements of generalised truths that have been accumulated through the experiences of preceding generations. There educational value lies in the fact that they are used by elders to teach 
youngsters about experiences of the past that they should emulate or avoid as well as evoke deepseated reflection in the listener and motivate one towards moral and spiritual action.

Proverbs are for Chagga people, as Mosha (2000) observes, one of their four treasured possessions: land, cattle, water and proverbs. $\mathrm{He}$ further expounded that land, culture, and water nourish their economy and bodies, whereas proverbs (wisdom, enlightenment, inspirations) nourish their moral integrity. Among the Abagusii an elder will say to a young man who shuns the duty of protecting the community: Nguru chiamomura Nchogu eguatia mbara (A young man's ability is equated to an elephant splitting wood). In his book Non-western Educational Traditions, Reagan (2005) argued that the basic idea underlying proverbs is that such sayings provide a succinct, easily remembered summaries of important ideas and experiences that are part of the shared cultural knowledge of the community.

Riddles, as Mapara (2009) notes, were also used to foster quick thinking on the part of the youngsters. Riddles have proven that indigenous knowledge systems are not something that is static, 
but a form of education and entertainment that some people today call edutainment, that is a combination of education and entertainment. In his outstanding study of indigenous systems of Chagga people in Tanzania, Mosha (2000) writes that, "riddling helps significantly in the development of language skills, logic, and arithmetical thinking." He further notes, riddling is significant in transmission of indigenous systems of education in the following ways:

- It assists listeners, especially young ones, to know and appreciate the usefulness and awesomeness of cosmic phenomena around them.

- Riddles give environmental education.

- Numerous African riddles give excellent intellectual training in mathematics and logical thinking.

Examples of Abagusii riddles, and their correct responses, include:

- Question: Chingondi ibere koru Nyakongo? (Two Sheep lead down the mountain?)

$$
\Rightarrow \text { Answer: Amamira (Nostrils) }
$$


- Question: Enyomba yaane yaagaacheirie egesigisa ekemo? (The house is supported by one pole?)

$\Rightarrow$ Answer: Oboba (Mushroom)

It is worth mentioning that in a bid to educate and mould the heart, soul and the body of individuals in the society, indigenous people significantly used riddles. As Sifuna (2006) added: "riddles dealt with issues pertaining to protection of the homestead against enemies, committing adultery and many others."

Writing about indigenous knowledge systems in Zimbabwe, Mapara (2009) noted that songs are another tool that was used as a form of education. $\mathrm{He}$ further observed that they could be used to memorise the qualities of a good wife/husband as is given in the songs "Sarura wako" (Take your pick) or to teach about chiefs and trees that are found in one's area of residence as is given in the songs "Dudu muduri" and "Tsatsa ndikatsandika." As Mosha (2000) aptly puts it: "Good songs goes beyond the intellect straight into our hearts and there evokes reflection, intense feelings, inspiration, and a strong feeling of connectedness with those around us and with all that is." When these forms of education are compared to 
the Western ones, as Mapara (2009) observes, for example the English nursery rhymes and songs, it can be observed that these do not relate to the African child's experiences. In fact, the education that Africans have inherited from the West has not empowered them, but has disabled them and has sold them the lie that they should be employed to make progress in life and to raise the standard of living.

It needs, however, to be pointed out that not all indigenous practices as WB (1998) contends are beneficial to the sustainable development of a local community and not all indigenous knowledge can provide the right solution for a given problem. Typical examples are slash and burn agriculture; female circumcision; overgrazing practices by pastoral communities such as Maasai of Kenya and use of indigenous farm equipment such as hoe that espouses small scale farming practices that has rendered communities incapable of sustaining adequate food reserves in a bid to combat hunger. Therefore, before adopting indigenous knowledge, integrating it into development programs, or even disseminating it, practices need to be dissected for their appropriateness just as any other technology. In addition to scientific proof, local evidence and 
the socio-cultural background in which the practices are embedded also need consideration in the process of validation and evaluation.

\section{Sustainable Development}

Sustainable development is a key concept in debates on development issues. As earlier discussed, it is the development that meets the needs of the present generation without compromising the ability of future generations to meet their needs. The concept of sustainable development as GoK (2007) notes emerged in the 1980 s in response to a growing realisation that economic and social activities have potential to compromise environmental quality as well as lower the productive potential of natural resources. It takes into account society, environment and economic factors conceptualized as pillars in order to ensure a more balanced form of development.

The World Summit of Sustainable Development, held at the end of August 2002 in Johannesburg, South Africa, issued the Johannesburg Declaration on Sustainable Development which once more reaffirmed the importance of eradicating poverty, a fair and just 
allocation of resources and the removal of "the deep fault line that divides human society between the rich and the poor and the ever-increasing gap between the developed and the developing world which pose a major threat to global prosperity and stability" (Skattom, 2009).

According to UNESCO (2007) the following are the essential characteristics of education for sustainable development:

- It is based on the principles and values that underlie sustainable development; deals with the well-being of all three realms of sustainability - environment, society and economy;

- promotes lifelong learning;

- is locally relevant and culturally appropriate;

- is based on local needs, perceptions and conditions, but acknowledges that fulfilling local needs often has international effects and consequences;

- engages formal, non-formal and informal education; 
- accommodates the evolving nature of the concept of sustainability;

- addresses content, taking into account context, global issues and local priorities;

- builds civil capacity for community-based decision-making, social tolerance, environmental stewardship, adaptable workforce and quality of life;

- is interdisciplinary: no one discipline can claim ESD as its own, but all disciplines can contribute to ESD;

- Uses a variety of pedagogical techniques that promote participatory learning and higher-order thinking skills.

Using indigenous knowledge in sustainable developing programmes gives it legitimacy and credibility in the eyes of both local people and outside scientists, thereby increasing cultural pride and motivation to solve problems with local ingenuity and resources (UNESCO, 2008) 


\section{Conclusion}

There is a constant need to respect, preserve and maintain knowledge, innovations and practices of indigenous communities embodying traditional life-styles and that would be very much relevant for the maintenance of sustainability in environment, ecosystem, and nature. It needs, however, to be noted by policy makers, educators and all educational stakeholders that the education that Africans have inherited from the West has not fully empowered us; it has disabled us to some extent and has sold the lie that we should be employed to make progress in life and to raise the standard of living. It is my contention that our education system needs to pay attention to the following critical issues in a bid to espouse holistic education and sustainable development in an African context:

- Redefining education to have a holistic perspective

- Supporting conservation of biodiversity to sustain life

- The relationship between science and indigenous knowledge to be emphasised

- There is need to contest decolonization of the mind and ethnocentrism 
- There is need to support moral education to inculcate fundamental human virtues

- A re-definition of sustainable development that emphasises the importance of indigenous knowledge

- There is need for teachers and students to gain enhanced respect for local culture, its wisdom and its ethics, and provides ways of teaching and learning locally relevant knowledge and skills. 


\section{References}

Ashok, D. G. (2011). Does indigenous knowledge have anything to deal with sustainable development? Antrocom online journal of anthropology vol.7. no.1.

Asma, I. W. (2012). Traditional knowledge on genetic resources: Safeguarding the cultural sustenance of indigenous communities. Asia Social Science Journal vol. 8. No.7.

Barasa, D. (2005). Indigenous knowledge systems and sustainable development in Africa: Case study on Kenya. A paper presented at the international conference Vrije Universiteit Brussel.

Bogonko, S. N. (1992). A history of education in Kenya. Nairobi: Evans Brothers Kenya Limited.

Cheserek, G. (2005). Indigenous knowledge in water and watershed management: Marakwet conservation strategies and techniques. A research paper presented at Moi University.

Crawford, L., and Rossiter, M. (1993). The Future of Holistic Education: The Recession We Had to Have? Curriculum Perspectives, 13, 1, 37-46.

Emeagwali, G. (2003). African indigenous knowledge systems: Implications for the curriculum. www.africanhistory.net 
GoK. (2008). Education for sustainable development implementation strategy. Nairobi: Government printer.

GoK. (2007). Kenya vision 2030: A globally competitive and prosperous Kenya. Nairobi: Government printer

IFAD (2003) Indigenous Peoples and Sustainable Development, Roundtable Discussion Paper for the Twenty-Fifth Anniversary Session of IFAD's Governing Council.

Mapara, J. (2009). Indigenous knowledge systems in Zimbabwe: Juxtaposing postcolonial theory. Journal of Pan African Studies, vol.3, No.1.

Mosha, R. (2000). The heartbeat of indigenous Africa. New York: Routledge.

Nyambura, S. (2008). Caught-in-between: Exploring the complexities of school vandalism. Nairobi: Paulines Publications Africa.

Ochieng, P. (2012, June 10). The paradox of Kenya's uneducated elite. Sunday Nation.

Ocholla, N. D. (2010). Marginalized knowledge: An agenda for indigenous knowledge development and integration with other forms of knowledge. Department of Library and International Science, University of Zululand. 
Reagan, T. (2005). Non-western educational traditions: Indigenous approaches to educational thought and practice. New Jersey: Lawrence Erlbaum Associates Inc. Publishers

Sifuna, D. N. (2006). Traditional systems of education in Africa: Africa indigenous education and Islamic education. In D. Sifuna, F. Chege, I. Oanda (Eds), Themes in the study of foundations of education (pp. 60-65), Nairobi: Jomo Kenyatta Foundation.

Skattom, I. (2009). Culture and language in Education: tools for development. Norad Report.

Subtle, D. (2009). The role of education in development. MESCI.

Susan, A. K. (2012). Holistic education and sustainable development. http:// motherearthrights.org/2010/08/18/harmony-withnature-report-of-the-un-secretary-general/

UNDSD. (2005-2014). Education for Sustainable Development. New York: United Nations. www.unesd.unesco.org 